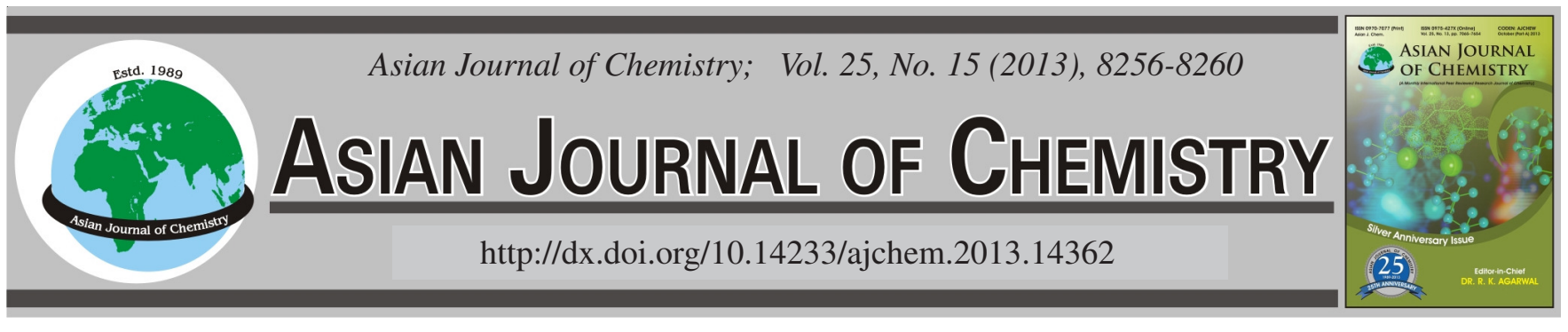

\title{
Application of Taguchi Method for Optimization of Polyol Ester Production by Esterification of Neopentyl Glycol with Hexanoic Acid
}

\author{
R.N.M. KAMIL ${ }^{1, *}$, S. YUSUP ${ }^{1}$ and L. ISMAIL ${ }^{2}$
}

${ }^{1}$ Department of Fundamental and Applied Science, Universiti Teknologi Petronas, Universiti Teknologi Petronas, Bandar Seri Iskandar, 31750 Tronoh, Perak, Malaysia

${ }^{2}$ Department of Chemical Engineering, Universiti Teknologi Petronas, Bandar Seri Iskandar, 31750 Tronoh, Perak, Malaysia

*Corresponding author: Fax: +60 5 3655905; Tel: +60 5 3687681; E-mail: ruzaimah_nikmkamil@ petronas.com.my

(Received: 13 October 2012;

Accepted: 16 August 2013)

AJC-13927

\begin{abstract}
Production of polyol ester from esterification of hexanoic acid (HA) and neopentyl glycol (NPG) was investigated. An optimization experiment, using a Taguchi L9 experimental layout, was used to examine the effect of temperature, pressure, HA:NPG ratio and catalyst amount. The effects of pressure $(0.5,25$ and $50 \mathrm{kPa})$; temperature $(423,453$ and $483 \mathrm{~K})$; catalyst amount $(0.5,1.0$ and $1.5 \%$ w/w) and HA:NPG ratio $(1.5: 1,3: 1$ and $6: 1)$ were investigated and found to have impacts on the reaction. The percentage contribution of each factors are 43.9, 38.8, 4.3 and $12.9 \%$, respectively. At the optimal reaction conditions of $423 \mathrm{~K}, 0.5 \mathrm{kPa}$, sulfuric acid catalyst $0.5 \%$ w/w and HA:NPG ratio (3:1) more than $99 \%$ w/w neopentyl glycol ester was obtained. Confirmation experiments were performed to demonstrate the effectiveness of this approach and characterization of neopentyl glycol ester was characterized using FTIR and ${ }^{1} \mathrm{H}$ NMR.
\end{abstract}

Key Words: Neopentyl glycol-based polyol esters, Esterification, Optimization, Taguchi method.

\section{INTRODUCTION}

Environmental awareness has trigger the replacement of petroleum oils with synthetic esters. Demand for esters as base stock is growing in various industrial applications such as automotive, aviation, refrigeration, compressor, offshore drilling, etc. ${ }^{1,2}$ due to its excellent features. Esters are known for excellent viscosity $v s$. temperature relationship, improved properties at high and low temperatures, low volatility, additive solubility, lubricity, frictional properties and biodegradability ${ }^{3}$.

Although the present-day basestocks from synthetic esters could be formulated to be rapidly biodegradable, but the processing costs are still high. In recent years, increasing attention has been paid to biodegradable polyol esters due to their outstanding features. Polyol esters are made by reacting fatty acids (FAs) or fatty acid esters with polyhydric alcohol such as trimethylolpropane (TMP), neopentyl glycol (NPG) and pentaerythritol (PE). The present compound, neopentyl glycol ester was synthesized by esterification of neopentyl glycol with hexanoic acid using sulfuric acid as catalyst (Fig. 1). neopentyl glycol esters are used commercially in lubricants, plasticizer and cosmetics ${ }^{4}$.

Taguchi method was employed as a tool for systematic experimental design which allows several effects of variables to be simultaneously determined effectively and efficiently.

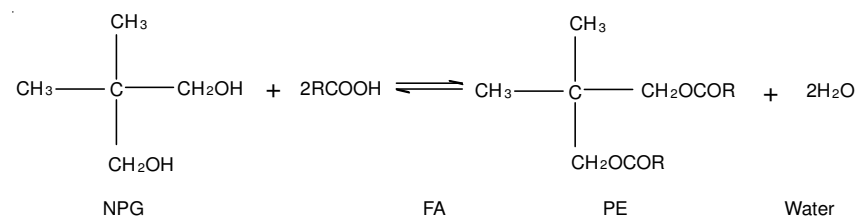

Fig. 1. Reaction between hexanoic acid (HA) and neopentyl glycol (NPG)

The combination of standard experimentation design techniques and analysis method in the Taguchi approach propose consistency and reproducibility rarely found in any statistical method $^{5}$.

The main objective of this work is to determine the optimum reaction condition for esterification of hexanoic acid (HA) and neopentyl glycol via employing the Taguchi method. The optimization experiment was performed using Taguchi L9 experimental layout and S/N concept of 'higher the better characteristics' for the conversion is referred. Four major controllable factors of the neopentyl glycol ester synthesis, namely, temperature, HA:NPG molar ratio, pressure and catalyst amount were investigated at three different range. The temperature range was 423 , 453 and $483 \mathrm{~K}$. The range of molar ratio of HA:NPG were $1.5: 1,3: 1$ and $6: 1$. The pressure was studied at $0.5,25$ and 50 $\mathrm{kPa}$ and the catalyst amounts were $0.5,1.0$ and $1.5 \mathrm{wt} \%$. Besides studying the optimization of neopentyl glycol ester production, chemical analysis was done by using FTIR and NMR. 


\section{EXPERIMENTAL}

Synthesis of neopentyl glycol ester was performed in a $250 \mathrm{~mL}$ three-neck flask equipped with a thermometer, a sampling port, a hot reflux condenser and a second condenser at lower temperature located after the first condenser. The condenser was connected to a vacuum line equipped with relief valve, accumulator and a vacuum trap. The flask was immersed in a temperature-controlled oil bath. Then the flask was filled with $100 \mathrm{~g}$ of hexanoic acid and a definite amount of neopentyl glycol under constant stirring. The weight of neopentyl glycol was determined based on the required molar ratio and the molecular weight of hexanoic acid. The mixture was then heated to the reaction temperature after which the catalyst was added. The reduced pressure was gradually applied to the system until it reached the desired pressure and maintained at the same value until the reaction was completed. Nine experiments demonstrated in the L9 Taguchi method were conducted randomly and repeated twice with standard deviation ranged between 0.15-4.5. The hexanoic acid conversion was reported as \% neopentyl glycol di-ester or as a total conversion in $\%$ to neopentyl glycol (mono- and di-esters of neopentyl glycol $)^{6}$.

From the neopentyl glycol conversion results, signal to noise ratio ( $\mathrm{S} / \mathrm{N}$ ratio) was calculated using larger-the-better quality characteristic for each of the nine experiments. $\mathrm{S} / \mathrm{N}$ ratio is the ratio of the mean (signal) to the standard deviation (noise) or representing the magnitude of the mean of a process compared to its variation. It provides a measure of the impact of noise factors on performance. The average performance of the controllable factor (e.g. temperature) was computed from the average value of $\mathrm{S} / \mathrm{N}$ ratio which corresponds to each temperature level (423, 453 and $483 \mathrm{~K})$. Similarly, the average performances of pressure, molar ratio of HA:NPG and catalyst amount at different levels were calculated in the same way.

Detection method: The polyol esters analysis was performed by gas chromatography using the method described by Yunus et al. ${ }^{7}$ on Shimadzu gas chromatography Model GC2010.

FTIR spectra was recorded in a FTIR - PIKE Miracle ATR, Digilab Scimitar Series on a Shimadzu Model 8400S Fourier transform infrared spectrometer equipped with ATR accessory (Pike Technologies, Inc., Madison, WI). The esters were scanned for wavelength from 4000-550 $\mathrm{cm}^{-1}$. NMR spectra were recorded on a Bruker (MA, USA) operating at $400 \mathrm{MHz}$ spectrometer. $\mathrm{CDCl}_{3}$ were utilized as solvent for all samples analyzed (neopentyl glycol, hexanoic acid, neopentyl glycol ester).

\section{RESULTS AND DISCUSSION}

The resulted data should be well presented by the form of schemes, figures, graphs, tables, reactions and equations. These items should be numbered clearly.

Experimental data analysis: Taguchi Method uses the $\mathrm{S} / \mathrm{N}$ (signal-to-noise) ratio and analysis of variance (ANOVA) to examine the scatter around a target value. The results of neopentyl glycol conversion shown as the response graph for significant factors: temperature, pressure, HA:NPG molar ratio and catalyst amount, are represented in Fig. 2(a-d), respectively. Fig. 2(a) illustrated the effect of temperature on
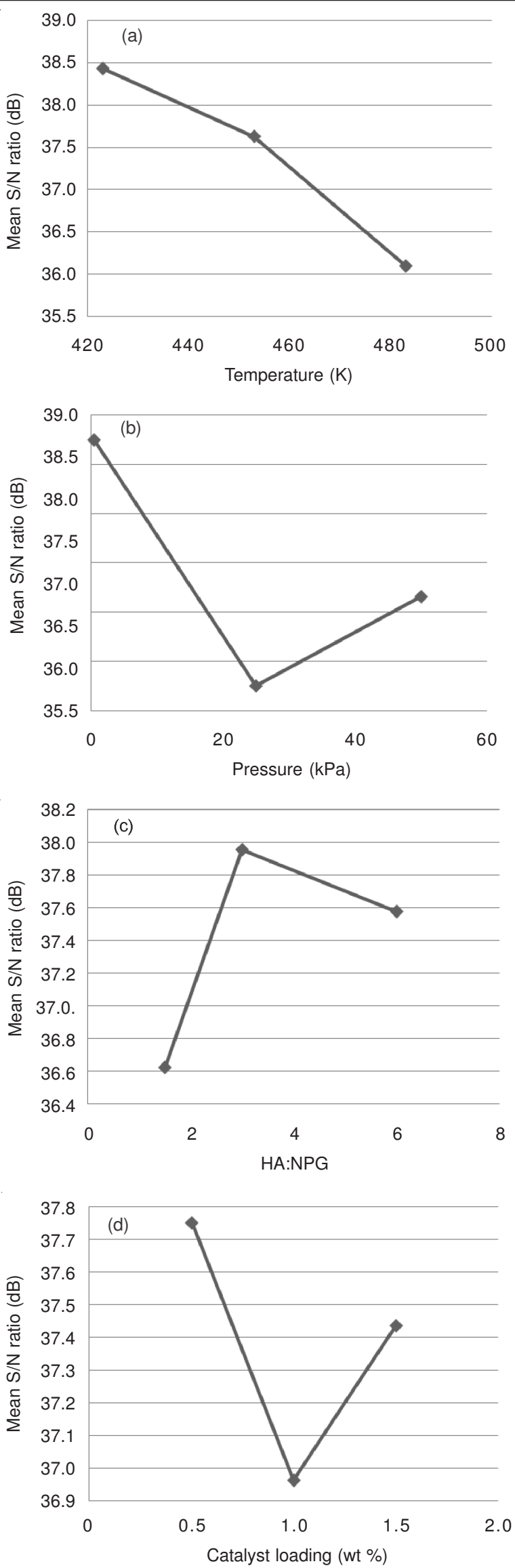

Fig. 2. Response graph for significant factors: temperature, reduced pressure, HA:NPG ratio and \% catalyst, respectively. The vertical axes show the values of the $\mathrm{S} / \mathrm{N}$ ratio. The lines represent the trend of each factor with respect to different levels 
neopentyl glycol conversion. The conversion to neopentyl glycol ester increased with decrease in temperature ranging from 423 to $483 \mathrm{~K}$. As the temperature decreased to $453 \mathrm{~K}$ the conversion increased rapidly, but slight increase in conversion was observed as the temperature was further decreased to 423 K. Eventhough, it has been reported that almost $100 \%$ conversion observed for the temperature of $503 \mathrm{~K}$ by Bondioli ${ }^{8}$, a conversion of $99 \%$ (Table-1) was observed at lower temperature of $423 \mathrm{~K}$ for the esterification of neopentyl glycol with hexanoic acid, in this study. The percentage contribution of temperature towards neopentyl glycol ester formation is around $38.8 \%$ of the total variation observed.

TABLE-1

RESULTS OF CONFIRMATION EXPERIMENT FOR NEOPENTYL GLYCOL ESTER. $\mathrm{A}_{1} \mathrm{~B}_{1} \mathrm{C}_{2} \mathrm{D}_{1}$ REFERS TO $423 \mathrm{~K}, 0.5$ $\mathrm{kPa}, 3: 1 \mathrm{MOLAR}$ RATIO AND $0.5 \mathrm{wt} \% \mathrm{H}_{2} \mathrm{SO}_{4}$, RESPECTIVELY

\begin{tabular}{lccc}
\hline & $\begin{array}{c}\text { Optimal } \\
\text { estimation }\end{array}$ & $\begin{array}{c}\text { Condition } \\
\text { experiment }\end{array}$ & $\begin{array}{c}\text { Difference } \\
(\%)\end{array}$ \\
\hline Level & $\mathrm{A}_{1} \mathrm{~B}_{1} \mathrm{C}_{2} \mathrm{D}_{1}$ & $\mathrm{~A}_{1} \mathrm{~B}_{1} \mathrm{C}_{2} \mathrm{D}_{1}$ & \\
$\begin{array}{l}\text { Neopentyl glycol ester } \\
\text { production (wt\%) }\end{array}$ & 100.0 & 99.0 & 1 \\
S/N value & & 39.91 & \\
\hline
\end{tabular}

The results given in Fig. 2(b), show the influence of pressure on the synthesis of neopentyl glycol ester by esterification. As the pressure increased from $0.5-25 \mathrm{kPa}$, conversion to neopentyl glycol ester decreased rapidly. However, as the pressure was further increased to $50 \mathrm{kPa}$, a slight increase in the conversion to neopentyl glycol ester was observed. The highest conversion was detected at the lowest at pressure of $0.5 \mathrm{kPa}$ within the stipulated pressure range. Several studies denote by reduced pressure are essential for the synthesis of various types of neopentyl polyol esters, to enhance forward reaction by removal of by-products such as water or methanol ${ }^{7,9}$. Application of reduced pressure is crucial in the esterification of neopentyl glycol with hexanoic acid. It removes water during neopentyl glycol esterification, which favours the forward reaction. The percentage contribution of pressure towards neopentyl glycol esterification was around $43.9 \%$.

Fig. 2(c) illustrates the effect of molar ratio on the esterification of neopentyl glycol with hexanoic acid. It can be seen from the figure that the conversion of neopentyl glycol ester increased with increase in molar ratio from 1.5:1-3:1, but slightly decreased when it was further increased to $6: 1$. It was anticipated that conversion will not be changed, with further increase in HA:NPG molar ratio due to the equilibrium achieved at this molar ratio as reported in the literature. Gryglewicz et al. ${ }^{9}$ reported that for transesterification of neopentyl glycol with FAME, equilibrium was achieved at FAME:NPG molar ratio of 2.4:1. The percentage contribution of HA:NPG molar ratio towards conversion to neopentyl glycol ester was $12.9 \%$.

Fig. 2(d) illustrates the effect of catalyst loading on neopentyl glycol conversion. The conversion to neopentyl glycol ester decreased with increase in catalyst amount up to $1.0 \mathrm{wt} \%$, but slightly increased when the catalyst amount was further increased to $1.5 \mathrm{wt} \%$. This is consistent with the findings of Uosukainen et al. ${ }^{6}$ for the transesterification of trimethylolpropane with rapeseed oil methyl ester. The study reported that the optimum catalyst weight percentage lays between 0.1 and $2.0 \%$. The percentage contribution of catalyst towards conversion to neopentyl glycol ester is $4.3 \%$.

Determination of optimum conditions and experimental verification for neopentyl glycol ester: As observed from Fig. 2(a-d), the maximum response for neopentyl glycol ester is obtained at $\mathrm{A}_{1}(423 \mathrm{~K}), \mathrm{B}_{1}(0.5 \mathrm{kPa}), \mathrm{C}_{2}$ (HA:NPG molar ratio $3: 1$ ) and $D_{1}$ (catalyst amount at $0.5 \mathrm{wt} \%$ ). Therefore, the maximum response conditions are most likely to produce the best result and thus, present the optimum condition for the synthesis of the polyol esters. Confirmation experiments for neopentyl glycol ester were performed to prove the effectiveness of the Taguchi method and the validity of the observed results. The estimated value of the conversion to neopentyl glycol ester was calculated and compared to the confirmation experimental results.

Table-1 illustrates the results of confirmation experiment compared to the optimal estimation for neopentyl glycol ester. From the experiment carried out at optimum conditions, conversion to neopentyl glycol ester achieved was $99.0 \%$ after $1 \mathrm{~h}$. The reaction was assumed to be completed as there were no further changes in the concentration of neopentyl glycol ester observed from gas chromatography analyses.

A study on the esterification of neopentyl glycol and hexanoic acid and other type of esters was reported by Knothe et $a l .{ }^{4}$. The reactants were mixed in toluene with $10 \mathrm{~mol} \%$ $p$-TsOH as catalyst. The reaction was carried out using DeanStark trap and reflux condenser. The reaction mixtures were refluxed for $6 \mathrm{~h}$ and the yields ranged from 70-97\% for the reactions. In this study, the neopentyl glycol ester conversion was achieved in $c a .1 \mathrm{~h}$ with conversion of $99 \%$, without the use of solvent for greener reaction.

The analysis of the confirmation experiment for polyol esters production has shown that Taguchi parameter design can successfully verify the optimum cutting parameters which are temperature $\left(\mathrm{A}_{1}\right)=423 \mathrm{~K}$, pressure $\left(\mathrm{B}_{1}\right)=0.5 \mathrm{kPa}, \mathrm{HA}: \mathrm{NPG}$ ratio $\left(\mathrm{C}_{2}\right)=3: 1$ and catalyst amount $\left(\mathrm{D}_{1}\right)=0.5 \mathrm{wt} \%$. Table- 1 shows the value of average polyol ester produced from the experiment compared to the estimated value. The GC chromatogram for the esterification of hexanoic acid and neopentyl glycol is shown in Fig. 3.

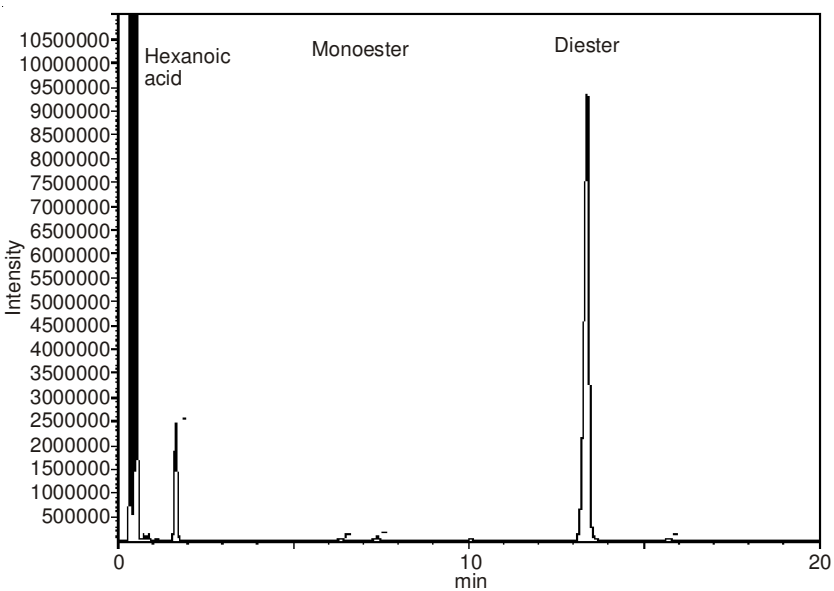

Fig. 3. GC Chromatogram of neopentyl glycol (NPG) ester derived from reaction between hexanoic acid and neopentyl glycol. Conditions: $423 \mathrm{~K}, 0.5 \mathrm{kPa}, \mathrm{HA}: \mathrm{NPG}$ molar ratio $3: 1$ and sulfuric acid catalyst at $0.5 \mathrm{wt} \%$ 


\section{Characterization of neopentyl glycol ester}

FTIR: The FTIR spectra obtained for the synthesized neopentyl glycol ester is shown in Fig. 4. The main functional group of neopentyl glycol ester such as ester carbonyl group, unsaturated and saturated hydrocarbon was determined by the infrared analysis. Every functional group of the neopentyl glycol ester was presented by different frequency as shown in Table-2. A prominent absorption peak for carbonyl group $(\mathrm{C}=\mathrm{O})$ occurs between 1630 and $1780 \mathrm{~cm}^{-1}$ and specifically for ester carbonyl group, the peak occurs between 1750-1735 $\mathrm{cm}^{-1}{ }^{10}$. As shown in Table-2, the peak for neopentyl glycol ester appears at $1735.8 \mathrm{~cm}^{-1}$ which is well within the Infrared region for ester carbonyl group. In addition to the carbonyl group neopentyl glycol ester illustrates peak at $1166 \mathrm{~cm}^{-1}$ region due to $\mathrm{C}-\mathrm{O}$ stretching frequency. Neopentyl glycol ester display both the carbonyl group $(\mathrm{C}=\mathrm{O})$ and the $\mathrm{C}-\mathrm{O}$ group. Therefore, it can be concluded that the product formed from the esterification of neopentyl glycol and hexanoic acid produces neopentyl glycol ester.

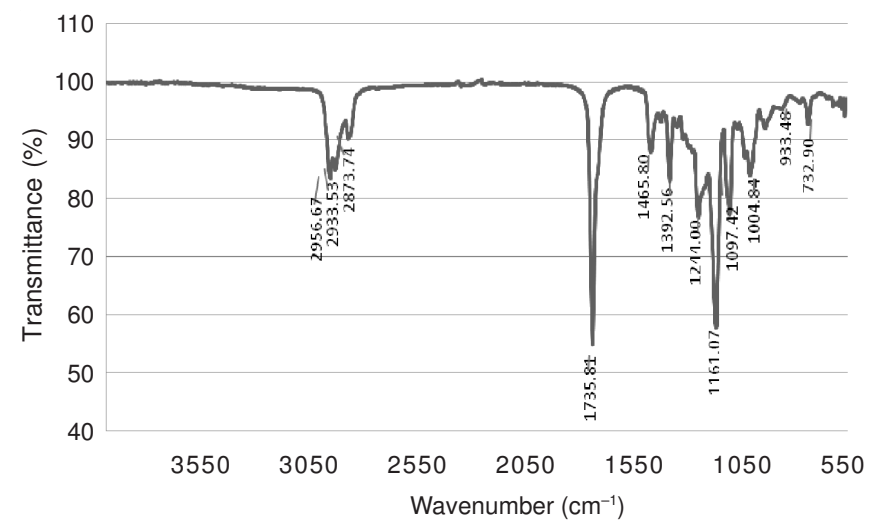

Fig. 4. FTIR spectrum of neopentyl glycol ester

\begin{tabular}{cc} 
TABLE-2 \\
FREQUENCY AND THE ASSIGN OF FUNCTIONAL \\
GROUP FOR NEOPENTYL GLYCOL ESTER \\
\hline Frequency $\left(\mathrm{cm}^{-1}\right)$ & Functional group \\
\hline- & $\mathrm{C}-\mathrm{H}$ stretching from $\mathrm{H}-\mathrm{C}=\mathrm{C}$ \\
2956.6 & $\mathrm{C}-\mathrm{H}$ stretching from $\mathrm{CH}_{2}$ and $\mathrm{CH}_{3}$ \\
2873.7 & $\mathrm{C}-\mathrm{H}$ stretching from $\mathrm{CH}_{2}$ and $\mathrm{CH}_{3}$ \\
1735.8 & $\mathrm{C}=\mathrm{O}$ stretching \\
1465.8 & $\mathrm{H}-\mathrm{C}-\mathrm{H}_{\text {bending }}$ \\
1392.6 & $-\mathrm{C}\left(\mathrm{CH}_{3}\right)_{2}$ \\
1166.1 & $\mathrm{C}-\mathrm{O}$ stretching \\
732.9 & $\mathrm{C}-\mathrm{H}$ rock \\
\hline
\end{tabular}

${ }^{1}$ H NMR: The ${ }^{1} \mathrm{H}$ NMR spectra of starting materials, neopentyl glycol, hexanoic acid and neopentyl glycol ester are shown in Fig. 5. Table-3 illustrates the chemical shifts and proton signals of neopentyl glycol, hexanoic acid and neopentyl glycol ester As obvious from the figure, the esterification of neopentyl glycol with hexanoic acid produces neopentyl glycol ester as indicated by the occurrence of a new signal from the neopentyl glycol ester spectrum. The new ${ }^{1} \mathrm{H}$ signal is detected at chemical shift of $3.83 \mathrm{ppm}$ which is located within the ester region. The signal corresponds to the new ester bond formed, which is the signal of the methylene protons bound to -O of the carboxylic acid ester group. The new signal

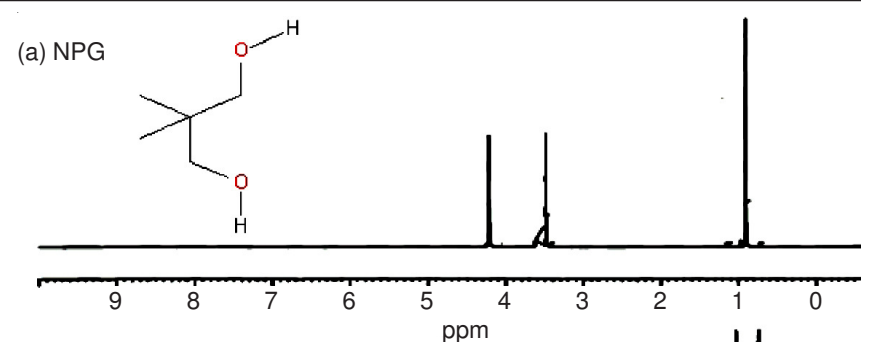

(b) Hexanoic acid
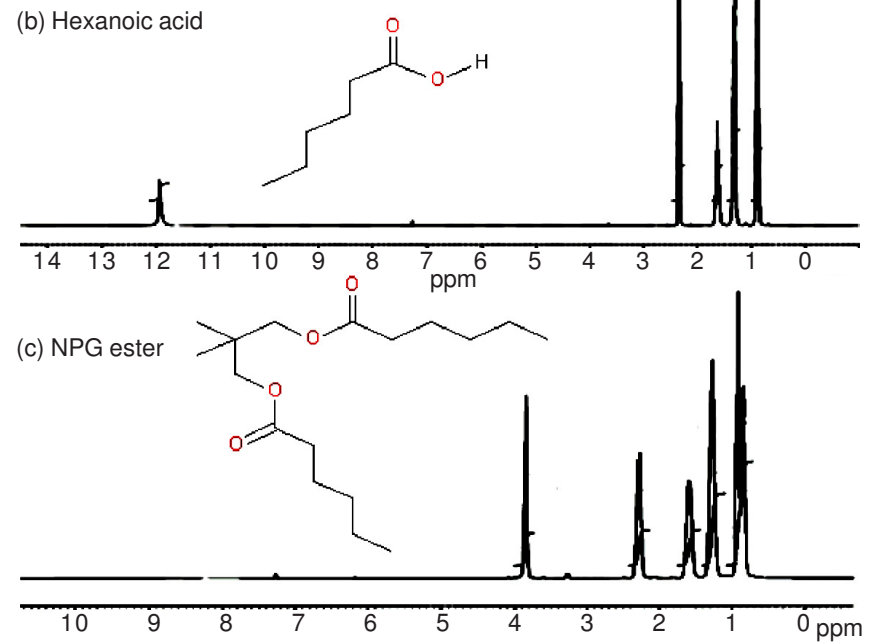

Fig. 5. $\quad{ }^{1} \mathrm{H}$ NMR spectrums (a) neopentyl glycol, (b) hexanoic acid and (c) neopentyl glycol ester

\begin{tabular}{cccl}
\multicolumn{4}{c}{ TABLE-3 } \\
\multicolumn{4}{c}{$\begin{array}{c}\text { CHEMICAL SHIFT AND PROTON SIGNALS } \\
\text { OF NPG, HA AND NPG ESTER }\end{array}$} \\
\cline { 1 - 3 } NPG & HA & NPG ester & \multicolumn{1}{c}{ Type of proton } \\
\cline { 1 - 3 } NPG & $0.87-0.91$ & $0.86-0.91$ & Alkyl, $\mathrm{RCH}_{3}$ \\
\cline { 1 - 3 }- & $1.29-1.33$ & 1.26 & Alkyl, $\mathrm{RCH}_{2} \mathrm{CH}_{3}$ \\
- & $1.62-1.65$ & $1.57-1.59$ & Alkyl, $\mathrm{ROCCH}_{2} \mathrm{CH}_{2} \mathrm{CH}_{3}$ \\
- & $2.31-2.36$ & $2.23-2.28$ & Alkyl, $\mathrm{ROCCH}_{2} \mathrm{CH}_{2} \mathrm{CH}_{3}$ \\
3.48 & - & - & Alcohol, $\mathrm{HOCH}_{2} \mathrm{R}$ \\
- & - & 3.83 & Ester, $\mathrm{RCH}_{2} \mathrm{OOCR}$ \\
4.18 & - & - & Alcohol hydroxyl, $\mathrm{ROH}$ \\
- & 11.92 & - & Carboxylic, $\mathrm{RCOOH}$ \\
\hline
\end{tabular}

denotes the formation of a new bond produced when neopentyl glycol ester was formed.

As shown in Table-3, the chemical shift for the esterification of neopentyl glycol and hexanoic acid was observed at 3.83 (the new ester group formed), 2.23-2.28 (Alkyl, ROCCH $\mathrm{CH}_{2} \mathrm{CH}_{3}$ ), 1.57-1.59 (alkyl, ROCCH${ }_{2} \mathrm{CH}_{2} \mathrm{CH}_{3}$ ), 1.26 (alkyl, $\mathrm{RCH}_{2} \mathrm{CH}_{3}$ ) and 0.86-0.91 (alkyl, $\mathrm{RCH}_{3}$ ). Similar ${ }^{1} \mathrm{H}$ NMR chemical shift was reported by Knothe et al. ${ }^{4}$ for the esterification reaction between hexanoic acid with neopentyl glycol. The ${ }^{1} \mathrm{H}$ NMR chemical shift observed by Knothe et al. ${ }^{4}$ was reported at 3.84, 2.27, 1.58, 1.29-1.24, 0.92 and 0.86 , which are similar to the ${ }^{1} \mathrm{H}$ NMR signal obtained from the synthesized neopentyl glycol ester from this work. Furthermore, all the peaks were confirmed using NMR analysis software and have similar chemical shift to the one synthesized in this work. Thus, it can be concluded that the neopentyl glycol ester synthesized from this experimental work through the esterification of neopentyl glycol and hexanoic acid is completed. 
A complete reaction is indicated by the disappearance of the chemical shift for alcohol group on the neopentyl glycol ester spectra. From Fig. 5 and Table-3, the signals of protons on the alcohol group of neopentyl glycol at $3.48 \mathrm{ppm}$ and $4.18 \mathrm{ppm}$ had disappeared from the ${ }^{1} \mathrm{H}$ NMR spectrum of neopentyl glycol ester which indicates complete reaction. Furthermore, the presence of partial ester was not detected on neopentyl glycol ester spectrum indicating that reaction was completed. This is consistent with results shown in Table-1 on Taguchi confirmation experiments which showed that the conversion to neopentyl glycol ester proceeds to $99 \%$ completion.

\section{Conclusion}

The synthesis of hexanoic acid-based neopentyl glycol ester was optimized using Taguchi L9 experimental layout to study the effect of temperature, pressure, HA:NPG molar ratio and catalyst amount. Statistical results showed that the order of importance of the variables are found to be pressure, temperature, HA:NPG molar ratio and catalyst. The optimum reaction conditions are identified to be $423 \mathrm{~K}, 0.5 \mathrm{kPa}$; sulfuric acid catalyst $0.5 \% \mathrm{w} / \mathrm{w}$ and HA:NPG molar ratio at 3:1. At this optimum condition the neopentyl glycol conversion obtained was $99 \%$. Analysis of the synthesized ester performed using FTIR and ${ }^{1} \mathrm{H}$ NMR confirms that the reaction was completed.

\section{ACKNOWLEDGEMENTS}

The authors acknowledged the research grant provided by Ministry of Higher Education (MOHE), Malaysia under Fundamental Research Grant Scheme (Project Code: FRGS/ 2/2010/SG/UTP/02/1).

\section{REFERENCES}

1. L.R. Rudnick, Synthetics, Mineral Oils and Bio-Based Lubricants: Chemistry and Technology, CRC Press, Taylor \& Francis Group, LLC, New York (2006).

2. R.N.M. Kamil, S. Yusup and U. Rashid, Fuel, 90, 2343 (2011).

3. F.T. Sejidov and Y. Mansoori, Ind. Lubric. Tribol., 59, 12 (2007).

4. G. Knothe, R.O. Dunn, M.W. Shockley and M.O. Bagby, J. Am. Oil Chem. Soc., 77, 8 (2000).

5. K.R.A. Roy, Primer on The Taguchi Method, Van Nostrand Reinhold, New York (1990).

6. E. Uosukainen, Y.Y Linko, M. Lamsa, T. Tervakangas and P. Linko, J. Am. Oil Chem. Soc. 75, 1557 (1998).

7. R. Yunus, A. Fakhrulrazi, T.L. Ooi, S.E. Iyuke and A. Idris, J. Oil Palm Res., 15, 42 (2003).

8. P. Bondioli, Topics Catal., 27, 77 (2004).

9. S. Gryglewicz, W. Piechocki and G. Gryglewicz, Bioresour. Technol., 87, 35 (2003)

10. T.W.G. Solomon, Organic Chemistry, John Wiley \& Sons (1988). 